\title{
TECHNOLOGIES FOR TESTING AND PRECISE MEASUREMENT IN HEAVY LIQUID METALS
}

\author{
Michal CHOCHOLOUŠEK, Zdeněk FULÍN, Zbyněk ŠPIRIT \\ CVR - Centrum výzkumu Řež, Husinec-Řež, Czech Republic, EU \\ michal.chocholousek@,cvrez.cz
}

https://doi.org/10.37904/metal.2019.841

\begin{abstract}
Centrum výzkumu Řež will carry out fatigue and fracture toughness tests in the frame of project Research for Sustainable Energy, in support of the European effort for the development of the Lead-cooled Fast Reactor as one of possible cooling systems of the Generation IV primary circuits. In order to progress material development for the future nuclear systems, an insight into the material properties at cycle fatigue loading and fracture toughness of candidate materials in Heavy Liquid Metals is required. The testing equipment has greater demands on precise measurement by comparison with Constant Extension Rate Tensile test previously performed in Centrum výzkumu Řež. Thus an extensometer for the liquid metal environment was developed to improve the accuracy of the measured results. The approach to testing conditions was upgraded with pumping circulation loop and possibility for sampling of liquid medium during the pretreatment. The progress in solving an issue of precise measurement is summarized and the adjustments of testing equipment are presented and justified.
\end{abstract}

Keywords: Heavy liquid metals, testing equipment, extensometer

\section{INTRODUCTION}

Lead-cooled Fast Reactor (LFR) is one of the possible cooling systems of the Generation IV. primary circuits. Therefore a considerable effort is focused on material testing in Heavy Liquid Metals (HLM) to obtain material properties of candidate materials. Testing in HLM environment is closely connected to the research and development of appropriate testing equipment. The effort is supported on the national and European level and Centrum výzkumu Řež (CVR) developed a testing cell for testing in $\mathrm{Pb}$ and PbBi-eutectic (LBE). HLM cell is continuously upgraded to more appropriately fulfill the requirements of the projects in progress.

The key issue of testing in HLM (Pb and LBE) is the controlling of oxygen amount in optimal range [1]. High oxygen level leads to creation of protective oxygen layer (see Figure 1), however high amount of oxygen products is undesirable for primary circuit operation. Low level of oxygen causes dissolution of protective oxygen layer and subsequently dissolution of particular alloying elements, e.g. Ni in nickel based alloys. As an example of oxygen layer dependence on oxygen concentration, Figure 1 shows the relation measured at $300{ }^{\circ} \mathrm{C}$ on ferritic-martensitic steel T91 in CVR.

Oxide layers chemical composition differs and it is affected by the environment. Figure 2 shows oxides layers formed on samples during the tests in air and LBE. The layers were examined by low discharge optical emission spectrometry (GD-OES). With GD-OES method, sputtering is used to record depth concentration profile of examined material. The intensity of the element is linked to its concentration and can be used for qualitative sample comparison, however it is not possible to calculate exact chemical composition. The layer formed on samples exposed to HML was compared with the layer formed during the test in air (both exposed at $400{ }^{\circ} \mathrm{C}$ ). The layer on the sample exposed in air contains iron and chromium oxides. Chromium intensity is low at the surface which is probably caused by slower sputtering of $\mathrm{Cr}$, not by its absence in the layer. From the depth of approx. $0.02 \mu \mathrm{m}$, the layer contains both iron and chromium oxides the layer is around $0.14 \mu \mathrm{m}$ thick. The layer created in LBE environment has different composition. First there is approx. $0.04 \mu \mathrm{m}$ thick oxide layer without any chromium. Thereafter chromium concentration rises while the oxygen is still present. 


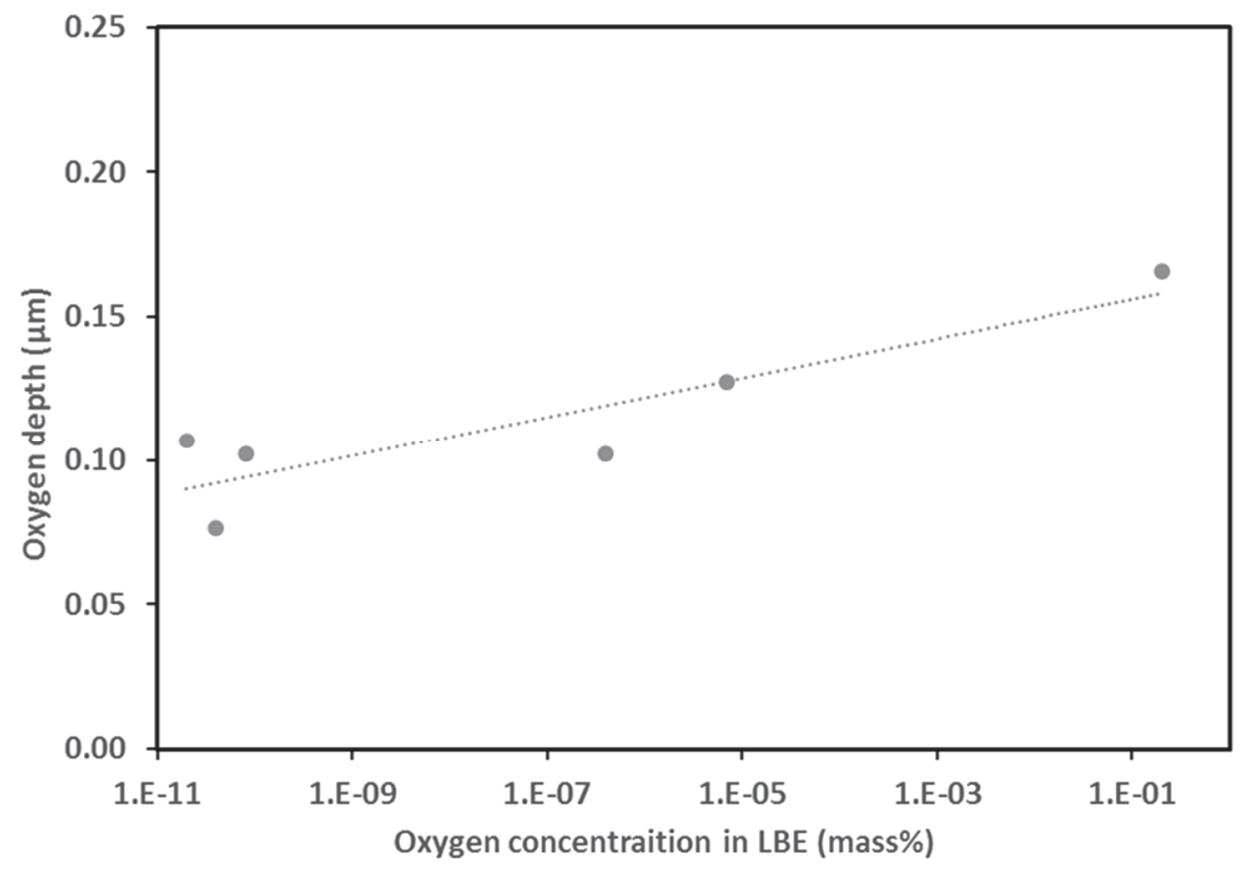

Figure 1 Dependence of oxygen depth (informative values) measured on T91 steel tested at constant strain rate $\left(10^{-6} \mathrm{~s}^{-1}\right)$ and at $300^{\circ} \mathrm{C}$ in air and LBE with controlled oxygen (mass. \%).

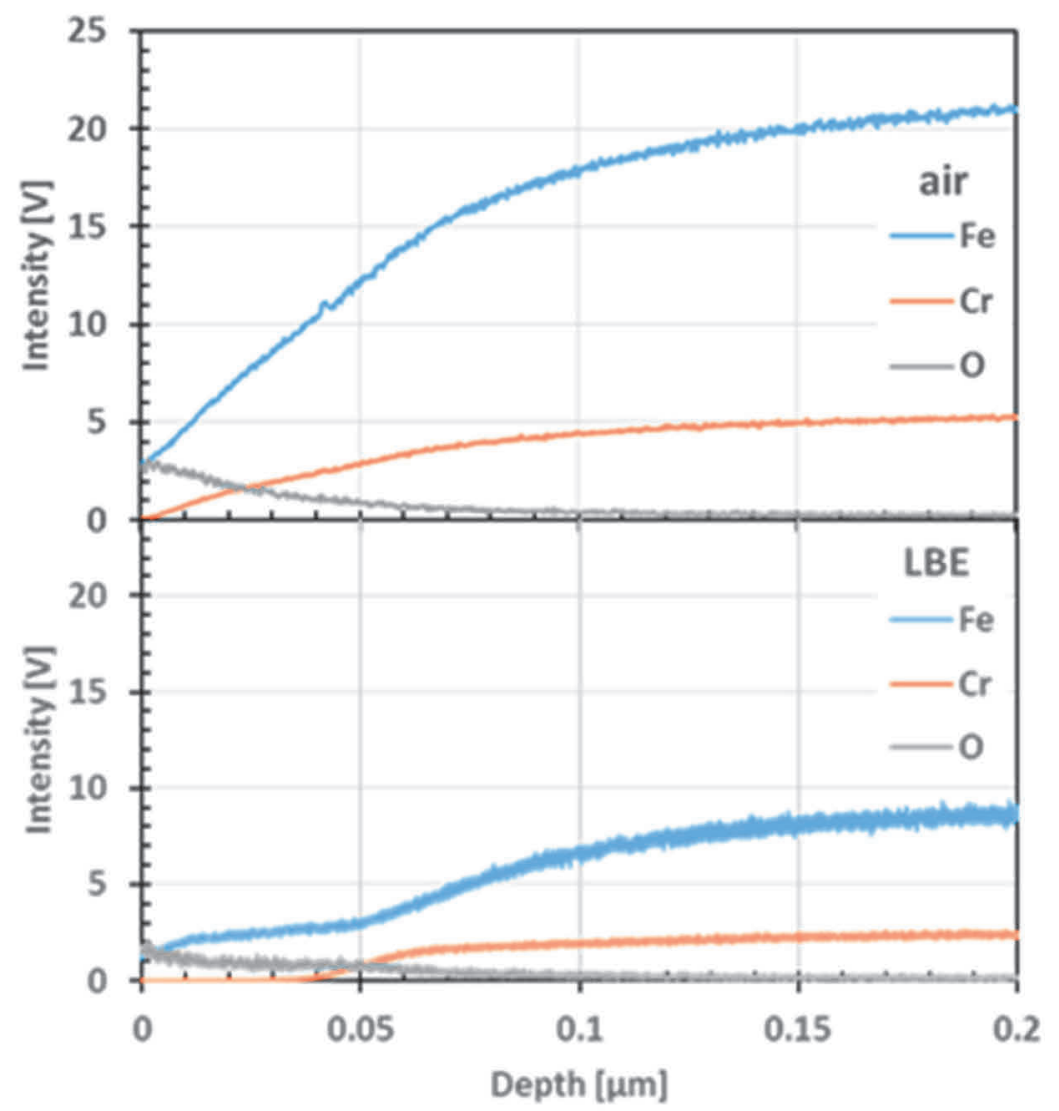

Figure 2 Oxide layers formed on T91 steel samples examined by GD-OES in CVR, in air (top) and in LBE (bottom). Due to the lack of reference material, it was unable to calibrate the instrument to get quantitative analysis therefore presented results aren't listed as concentrations in absolute values. 
It means there is second layer consisting from $\mathrm{Cr}$-Fe oxides mix. As was observed before, the $\mathrm{Cr}-\mathrm{Fe}$ layer forms first under the original surface, after that some iron atoms move to the surface by diffusion and create the layer without chromium. This effect was observed before. [2] There was also an attempt to find correlation between oxygen concentration and layer thickness but the depth measurement comes with too big error to make accurate conclusions.

From the point of view of the mechanical testing, the goal of the gas regulation is to obtain a homogeneous HLM medium to minimize the inaccuracy of oxygen concentration caused by the environment and to receive the most reliable results. Another issue for HLM testing is to receive a precise deformation measurement. Compared to testing in air, extensometers for testing in HLM environment are generally not available and standard air extensometers are not suitable due to risk of its destruction, e.g. contamination by oxides on movable parts and then jamming. Using data from the testing machine crosshead is sufficient for informative measurement, however to obtain precise values for mechanical testing such as low cycle fatigue or fracture toughness requires in-situ extensometer. Thus CVR approached to development of its own measure equipment.

\section{RESULTS}

Testing system currently used in CVR consists of a testing cell and a gas regulation system with three $\mathrm{BiO}$ based oximeters. The gas input is on one place below the HLM level and below the specimen, near the bottom of the testing cell. The original conception is a circulation of HLM medium inside the cell caused by the gas inlet. However the results of cell operation show data scatter of oxygen concentration (see Figure 3). The differences between the particular oximeters are caused due to insufficient circulation of the HLM environment. Achieving more accurate evaluation of oxygen concentration thresholds requires homogenous environment. The applied solution is presented in Figure 4. As an upgrade of testing cell, a forced circulation loop was used.

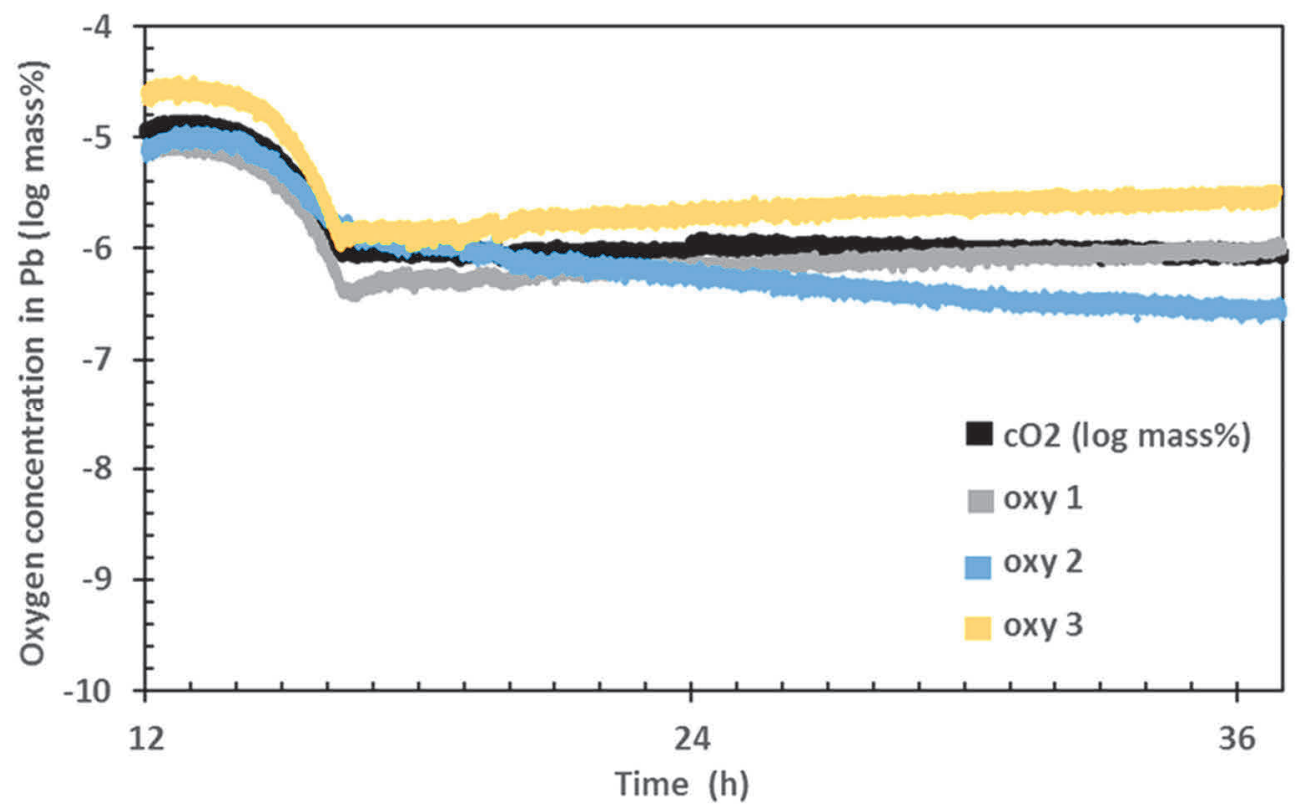

Figure 3 Oxygen concentration regulated in liquid $\mathrm{Pb}$ at $400^{\circ} \mathrm{C}$ : Data measured in 3 locations by 3 oximeters and final average value. Time course shows decreasing of oxygen after transfer of HLM to testing cell and subsequent regulation during the long-term test.

The loop consists of the pump able to move the liquid metal up - the direction of the circulation is from the bottom of the testing cell to upper inlet. Additional part is input for placing a magnesium tape, which reduces the oxygen concentration like argon-hydrogen gas mixture, however the reduction with $\mathrm{Mg}$ is significantly 
faster. The Mg-tape is used only for cases with high oxide pollution in tubes and it is not necessary to use it for standard situation. The loop is heated along the entire length to maintain the testing temperature constant. The heating is removable for easy access to loop (in case of accident or Mg-tape removing) and it is not in Figure 4. There is possibility of HLM flow regulation by controlling of pump's power. The flow can affect the material behavior in HLM, however its presence is closer to real operational conditions and its control allows perform tests of flow influence.

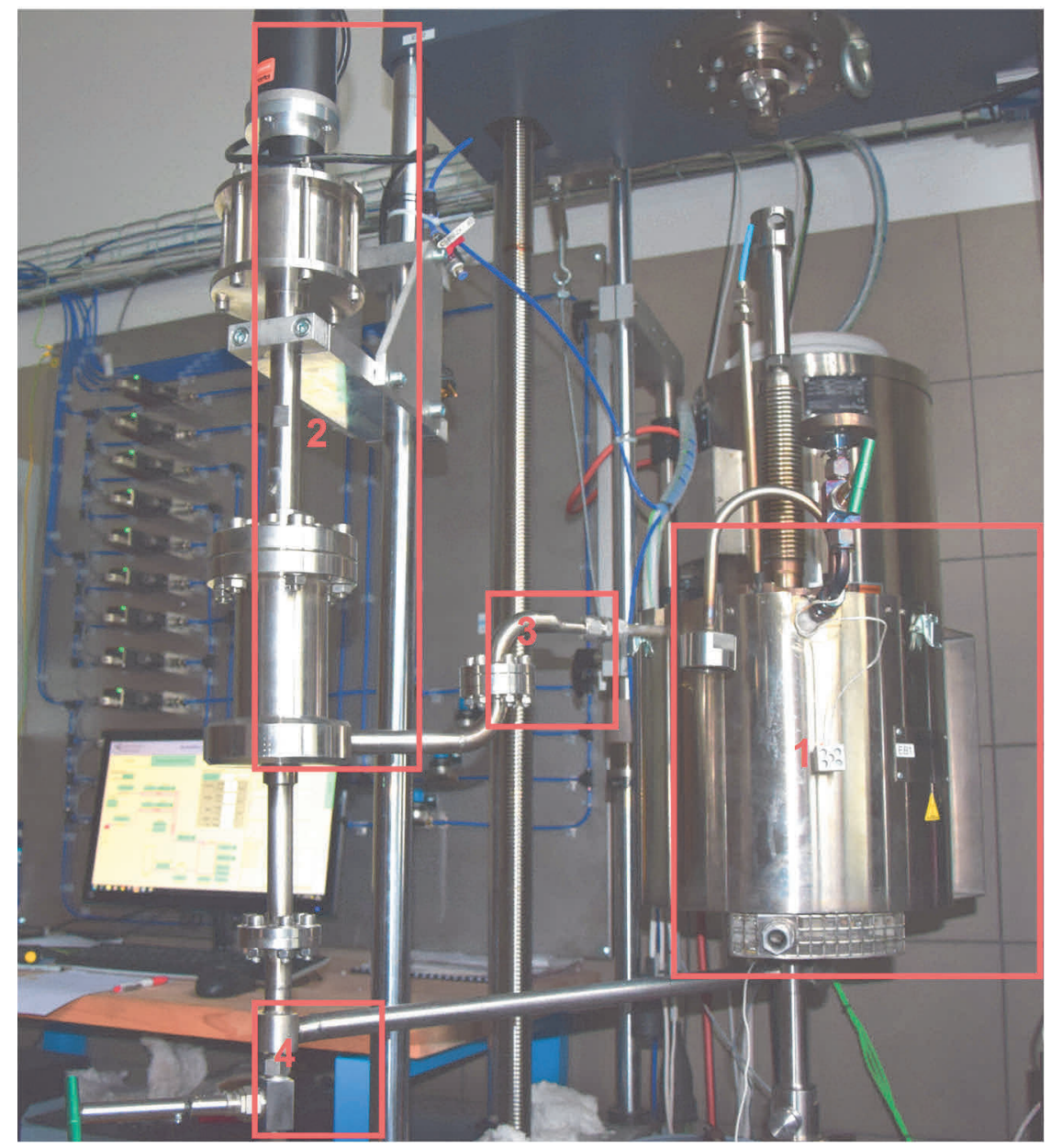

Figure 4 HLM testing cell with a circulation loop for liquid metal. 1 - Testing cell, 2 - pump, 3 - input for Mg-tape, 4 - HLM output.

The solution for the measurement in HLM is an extensometer showed in Figure 5. The basic construction uses standard rod-in-tube extensometer. Contrary to the test in air, HLM solution needs an ability to keep the protective gas atmosphere in the testing cell without influence on oxygen concentration in liquid metal environment. The measuring electronic needs to be protected from the heat transfer from the testing cell. Therefor the electronic is placed outside the testing system and there are two magnetic sensors used for mutual displacement measurement. The sensors are located at the end of rod and tube and they are placed inside a small chamber with additional gas inlet. The separate gas input has a function of prevention from HLM leakage into extensometer tubes. The measuring points are on the specimen fittings, however extensometer clips with different design can be fitted directly to the specimen (depends on specimen shape). The extensometer is equipped with springs which maintain preload between rod and tube. The preload prevents the failure of extensometer's contact. The accuracy of the extensometer depends on accuracy of magnetic sensor and the geometry. Therefore the accuracy of the extensometer can be validated on the calibrator device before the test performance. 


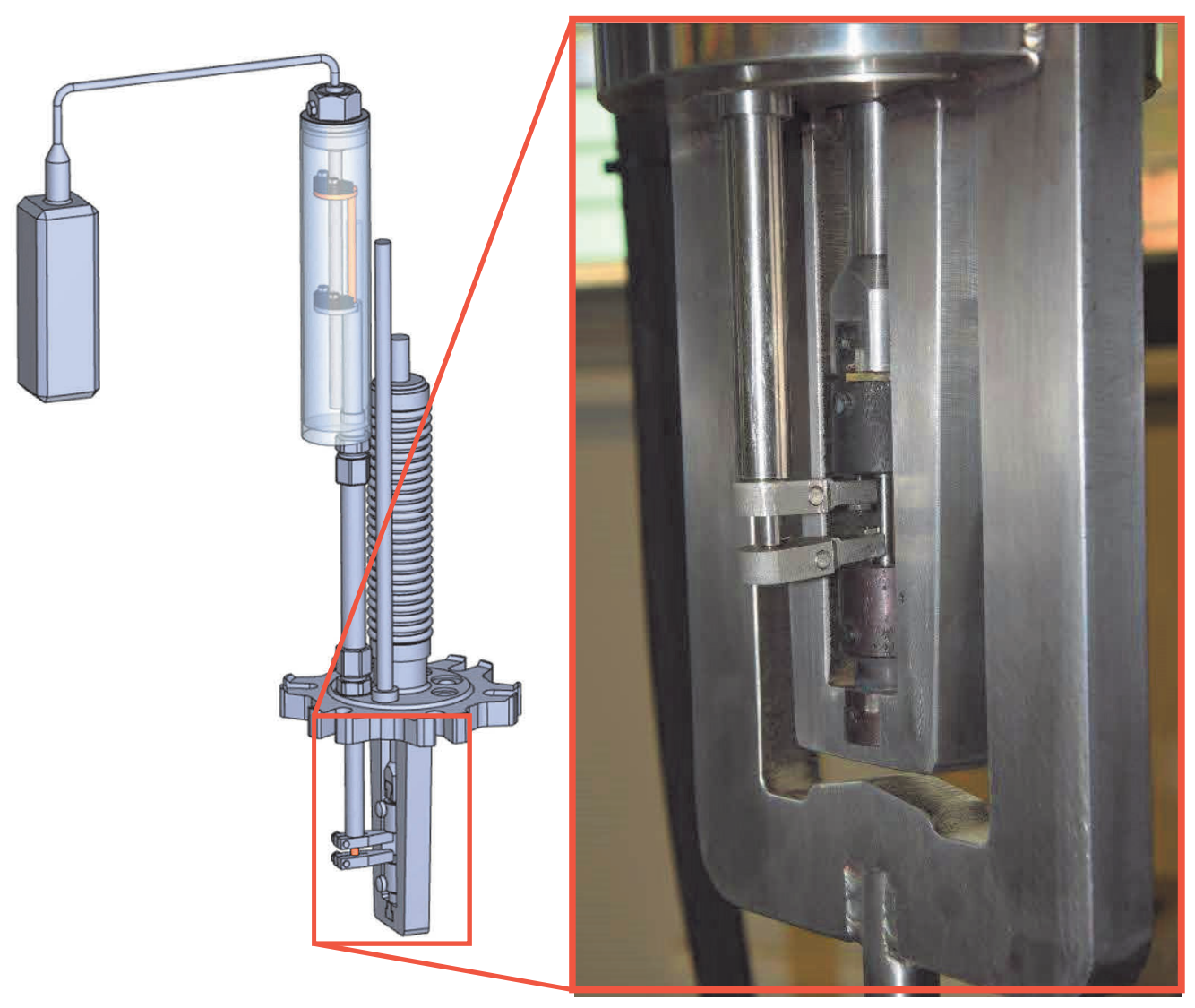

Figure 5 HLM extensometer: Model of the extensometer (left), attached extensometer on the model of HLM testing cell with a rod tensile specimen (right)

\section{CONCLUSION}

To obtain homogeneous Heavy Liquid Metals (HLM) environment, a circulation loop for liquid metal was added to the testing cell. The circulation has HLM flow control, which allows study of HLM flow influence. The extensometer for HLM testing was developed with ability to keep the protective gas atmosphere without influence on oxygen concentration in HLM.

\section{ACKNOWLEDGEMENTS}

The presented work was financially supported by the Ministry of Education, Youth and Sport Czech Republic Project LQ1603 (Research for SUSEN). This work has been realized within the SUSEN Project (established in the framework of the European Regional Development Fund (ERDF) in project CZ.1.05/2.1.00/03.0108). Also thanks to the company Škoda JS a.s., which was involved in the development and which produced equipment according to the requirements.

\section{REFERENCES}

[1] NUCLEAR ENERGY AGENCY ORGANISATION FOR ECONOMIC CO-OPERATION AND DEVELOPMENT Handbook on Lead-bismuth Eutectic Alloy and Lead Properties, Materials Compatibility, Thermal-hydraulics and Technologies, 2015 NEA No. 7268 ed. [online]; NEA OECD: Issy-les-Moulineaux, France, 2015; pp. 185-200. http://www.oecd-nea.org/science/pubs/2015/7268-lead-bismuth-2015.pdf

[2] MÜLLER, G., SCHUMACHER, G. and ZIMMERMANN, F. Investigation on Oxygen Controlled Liquid Lead Corrosion of Surface Treated Steels. Journal of Nuclear Materials. 2000. vol. 278, p. 85-89. 